\title{
Comparison of image features and diagnostic value of color Doppler ultrasound and two-dimensional ultrasound in the diagnosis of ovarian sex cord-stromal tumors
}

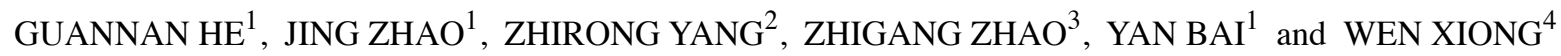 \\ Departments of ${ }^{1}$ Ultrasound, ${ }^{2}$ Pathology and ${ }^{3}$ Gynaecology, Sichuan Provincial Hospital for Women and Children, \\ Chengdu, Sichuan 610031; ${ }^{4}$ Department of Ultrasound, Sichuan Provincial People's Hospital, \\ University of Electronic Science and Technology of China, Chengdu, Sichuan 611731, P.R. China
}

Received August 20,2019; Accepted December 19, 2019

DOI: $10.3892 / \mathrm{ol} .2020 .11704$

\begin{abstract}
Clinical value of color Doppler ultrasound and two-dimensional ultrasound in the diagnosis of ovarian sex cord-stromal tumors (OSCSTs) were explored. A total of 91 patients with positive OSCSTs admitted to Sichuan Provincial Hospital for Women and Children from May 2014 to June 2018 were selected as research objects. There were 48 patients diagnosed by color Doppler ultrasound technology as the color Doppler group and 43 patients diagnosed by twodimensional ultrasound technology as the two-dimensional ultrasound group. Results of ultrasound images in the two groups were compared, and the diagnostic value of two ultrasound techniques combined with detection of CA125 and CA199 for OSCSTs was compared. The real internal echo of color Doppler ultrasound was significantly higher than that of two-dimensional ultrasound $(\mathrm{P}<0.05)$. The blood flow signal of color Doppler ultrasound was significantly higher than that of two-dimensional ultrasound $(\mathrm{P}<0.05)$. The diagnostic sensitivity and diagnostic coincidence rate of color Doppler ultrasound for lymph node metastasis of OSCSTs were significantly higher than those of two-dimensional ultrasound $(\mathrm{P}<0.05)$. Color Doppler ultrasound combined with CA125 and CA199 detection has higher accuracy than two-dimensional ultrasound combination. In conclusion, both color Doppler ultrasound and two-dimensional ultrasound are used to observe OSCSTs for early diagnosis, but the sensitivity and diagnostic coincidence rate of color Doppler ultrasound for clinical diagnosis of OSCSTs are higher than those of two-dimensional ultrasound, so color Doppler ultrasound has higher diagnostic value in OSCSTs.
\end{abstract}

Correspondence to: Dr Wen Xiong, Department of Ultrasound, Sichuan Provincial People's Hospital, University of Electronic Science and Technology of China, 32 Western Second Section, First Ring Road, Qingyang, Chengdu, Sichuan 611731, P.R. China E-mail: vud441@163.com

Key words: color Doppler ultrasound, two-dimensional ultrasound, ovarian sex cord-stromal tumors, image features, diagnostic value

\section{Introduction}

Ovarian sex cord-stromal tumors (OSCSTs) are rare mixed ovarian tumors. OSCSTs are composed of stromal elements of gonads, sex cord-like cells or a plurality of luteinized cells in different differentiation stages in a single or mixed manner $(1,2)$. However, due to the non-significant specificity of its histological features, clinicopathological manifestations, physical examination and imaging features, it is difficult to differentiate OSCSTs from similar gynecologic tumors. Therefore, clinical diagnosis and differentiation are difficult, especially when judging the benign and malignant nature of tumors, and patients could miss the best treatment time $(3,4)$. Clinically, ovarian tumors are usually diagnosed by histopathological examination and surgery, and treated by surgical resection $(5,6)$. However, due to the relatively few clinical records and confirmed cases of OSCSTs, and insufficient cognition, no definite diagnosis can be made before surgery $(7,8)$.

Imaging examination plays an important role in the quantitative, and qualitative detection and diagnosis of ovarian tumors, of which ultrasound has the advantages of less radiation damage, simple operation and high resolution to soft tissue $(9,10)$. The existing two-dimensional ultrasound technology is relatively mature with widespread clinical application. It is the main method to examine ovarian tumors. The diagnostic accuracy has been improved in recent years through the use of high-frequency probes. However, it still has shortcomings, for example, poor diagnostic efficiency, obvious misdiagnosis rate, and low accuracy in judging pathological types or disease development degree, leading to an increase in the possibility of misdiagnosis and missed diagnosis $(11,12)$. Two-dimensional ultrasound is a section imaging technology, and color Doppler ultrasound provides real-time stereoscopic imaging on this basis. Color Doppler ultrasound has the advantages of short distance between probe and ovary, high resolution between blood vessel and ovary. When monitoring blood flow, it can make judgment according to the difference of blood flow distribution in ovarian masses $(13,14)$. It has been reported in literature (15) that color Doppler ultrasound is effective in detecting the success rate of blood flow signals of 
ovarian malignant tumors, providing more valuable information for the diagnosis and differentiation of lesions. This study compared the diagnostic value of two-dimensional ultrasound and color Doppler ultrasound for OSCSTs.

\section{Patients and methods}

General materials. A total of 91 patients with positive OSCSTs admitted to Sichuan Provincial Hospital for Women and Children (Chengdu, China) from May 2014 to June 2018 were selected as research objects, of whom 48 patients diagnosed by color Doppler ultrasound technology were the color Doppler group and 43 patients diagnosed by two-dimensional ultrasound technology were the two-dimensional ultrasound group. All the subjects were aged between 18 and 78 years, with an average age of $41.2 \pm 11.7$ years and BMI of $21.1 \pm 3.3 \mathrm{~kg} / \mathrm{m}^{2}$. Among them, there were 29 cases of granulosa cell tumors, 5 cases of thecoma, 20 cases of mixed tumors, 13 cases of supportive stromal cell tumors, 16 cases of sclerosing stromal tumors and 8 cases of fibrosarcoma. There were no significant differences in age, BMI, abdominal pain and ascites of patients between the two groups $(\mathrm{P}>0.05)$ (Table I).

Inclusion and exclusion criteria. Inclusion criteria: Patients diagnosed as OSCSTs by pathological diagnosis. Exclusion criteria: Patients previously treated for OSCST diseases; women with other malignant tumors; patients who were breast-feeding or pregnant; patients with cognitive impairment or communication impairment; patients with poor compliance.

All patients and their families agreed to participate in the experiment and signed an informed consent. The study was approved by the Medical Ethics Committee of Sichuan Provincial Hospital for Women and Children.

Experimental reagents and materials. The color Doppler diagnostic apparatus was purchased from Siemens (S2000) and LOGIQ (E9).

Ultrasound experimental methods. During the examination, the probe frequency is $4-8 \mathrm{MHz}$ in abdomen and 4-9 $\mathrm{MHz}$ in vagina. Stone amputation was performed when the bladder was empty. Internal echo and boundary of the two groups were observed and recorded by travaginal two-dimensional ultrasound, and color Doppler ultrasound was used to examine the section of the highest possibility at highest definition. The blood flow condition inside and around the tumor was observed and recorded, the location and size of ovarian tumor combined with abdominal two-dimensional ultrasound images were observed, the relationship between morphology and viscera and organs was summarized, and ascites was detected.

Detection method. Venous blood $(3 \mathrm{ml})$ was taken from fasting patients in the morning as examination specimen. After centrifugation at 1,500 $\mathrm{xg}$ for $5 \mathrm{~min}$ at normal temperature, the serum was taken and stored at $-20^{\circ} \mathrm{C}$. Electrochemiluminescence was used to detect serum CA125 and CA199. The steps were as follows: the serum sample was pre-treated with reducing reagents; CA125 and CA199 were placed at constant temperature for antigen-antibody complex; ruthenium-labeled and biotin-labeled antibodies were added, and after binding,

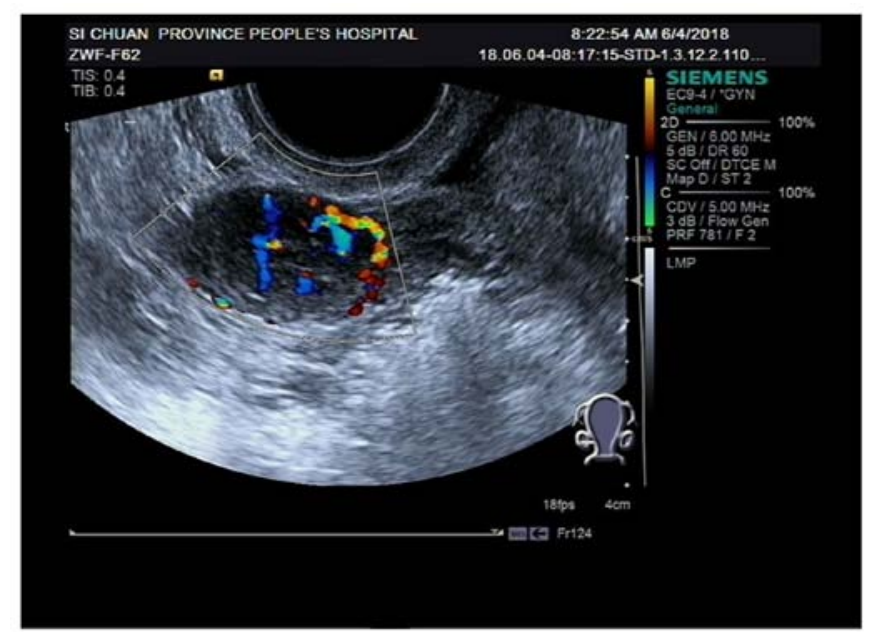

Figure 1. Color Doppler ultrasound image of patients with positive ovarian sex cord-stromal tumors.

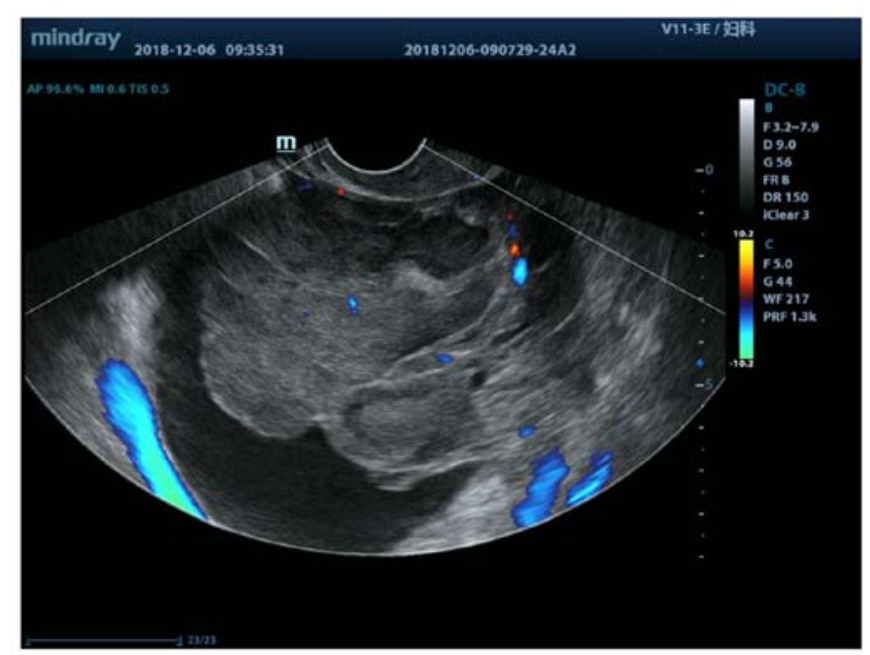

Figure 2. Color Doppler ultrasound image of patients with positive ovarian sex cord-stromal tumors.

magnetic beads were added to generate a solid phase complex. The magnetic beads are adsorbed and cleaned by the electrode. After the light-emitting reaction occurs, the sample to be tested and the light signal were examined. The weaker the light signal, the larger the amount of the sample to be tested. The normal value of serum CA125 is $0-35 \mathrm{U} / \mathrm{ml}$, and it is positive when $>35 \mathrm{U} / \mathrm{ml}$. The normal value of serum CA199 was $0-37 \mathrm{U} / \mathrm{ml}$, and it is positive when $>37 \mathrm{U} / \mathrm{ml}$. Any positive result of the index will be judged as positive.

Observation indicators. Color Doppler ultrasound and twodimensional ultrasound were used to measure size, form, boundary and location of tumors. The results of two ultrasound images for patients with OSCSTs were compared. The sensitivity, specificity and diagnostic accuracy of the two kinds of ultrasound in the detection of pathological signs of OSCSTs were compared.

Statistical methods. In this experiment, SPSS 19.0 statistical (Beijing ND Times Science and Technology Co., Ltd.) was 
Table I. General data of patients.

\begin{tabular}{|c|c|c|c|c|}
\hline Factors & $\begin{array}{c}\text { Color Doppler } \\
\text { ultrasound group } n=48\end{array}$ & $\begin{array}{l}\text { Two-dimensional } \\
\text { ultrasound group } n=43\end{array}$ & $\mathrm{t} / \chi^{2}$ value & P-value \\
\hline Age (years) & & & 0.002 & 0.967 \\
\hline$\leq 41$ & $27(56.25)$ & $24(55.81)$ & & \\
\hline$>41$ & $21(43.75)$ & $19(44.19)$ & & \\
\hline BMI $\left(\mathrm{kg} / \mathrm{m}^{2}\right)$ & & & 0.008 & 0.930 \\
\hline$\leq 21$ & $23(47.92)$ & $21(48.84)$ & & \\
\hline$<21$ & $25(52.08)$ & $22(51.16)$ & & \\
\hline Irregular vaginal bleeding & & & 0.402 & 0.526 \\
\hline Yes & $21(43.75)$ & $16(37.21)$ & & \\
\hline No & $27(56.25)$ & $27(62.79)$ & & \\
\hline Abdominal pain & & & 2.227 & 0.996 \\
\hline Yes & $29(60.42)$ & $26(60.47)$ & & \\
\hline No & $19(39.58)$ & $17(39.53)$ & & \\
\hline Ascites & & & 0.096 & 0.757 \\
\hline Yes & $9(18.75)$ & $7(16.28)$ & & \\
\hline No & $39(81.25)$ & $36(83.72)$ & & \\
\hline Typing & & & 0.488 & 0.993 \\
\hline Granulosa cell tumors & $15(31.25)$ & $14(32.56)$ & & \\
\hline Thecoma & $2(4.17)$ & $3(6.98)$ & & \\
\hline Mixed tumors & $11(22.92)$ & $9(20.93)$ & & \\
\hline Supportive stromal cell tumors & $7(14.58)$ & $6(13.95)$ & & \\
\hline Sclerosing stromal tumors & $9(18.75)$ & $7(16.28)$ & & \\
\hline Fibrosarcoma & $4(8.33)$ & $4(9.30)$ & & \\
\hline $\mathrm{C} 125(\mathrm{U} / \mathrm{ml})$ & $95.62 \pm 14.52$ & $98.63 \pm 15.45$ & 0.958 & 0.341 \\
\hline C199 (U/ml) & $97.46 \pm 15.73$ & $98.72 \pm 15.82$ & 0.381 & 0.705 \\
\hline $\operatorname{AFP}(\mu \mathrm{g} / 1)$ & $75.63 \pm 9.62$ & $76.36 \pm 9.93$ & 0.356 & 0.723 \\
\hline
\end{tabular}

Table II. Comparison of size, form, boundary and location of tumors under color Doppler ultrasound and two-dimensional ultrasound.

\begin{tabular}{lccc}
\hline $\begin{array}{l}\text { Features of } \\
\text { tumors }\end{array}$ & $\begin{array}{c}\text { Color Doppler } \\
\text { ultrasound group } n=48\end{array}$ & $\begin{array}{c}\text { Two-dimensional } \\
\text { ultrasound group } n=43\end{array}$ & $\begin{array}{c}\text { P-value } \\
\text { t/ } \chi^{2} \text { value }\end{array}$ \\
\hline $\begin{array}{l}\text { Tumor size } \\
\text { Form }\end{array}$ & $7.34 \pm 4.53$ & $7.51 \pm 4.46$ & 0.180 \\
Irregular & $3(6.25)$ & $2(4.65)$ & 0.112 \\
Regular & $45(93.75)$ & $41(95.35)$ & 0.738 \\
Boundary & $43(89.58)$ & $37(86.05)$ & 0.267 \\
Clear & $5(10.42)$ & $6(13.95)$ & 0.024 \\
Not clear & & $28(65.12)$ & 0.876 \\
Location & $32(66.67)$ & $15(34.88)$ & \\
Unilateral & $16(33.33)$ & & \\
Multilaterality & & & \\
\hline
\end{tabular}

used to make statistical analysis on the experimental data. Chi-square test was used for counting data, measuring data were expressed by mean \pm standard deviation and t-test was used for comparison between the two groups. Graphpad Prism8 was used to present the illustrations. $\mathrm{P}<0.05$ was considered to indicate a statistically significant difference. 
Table III. Comparison of results of two kinds of ultrasound images in patients with positive ovarian sex cord-stromal tumors.

\begin{tabular}{|c|c|c|c|c|}
\hline $\begin{array}{l}\text { Features of } \\
\text { imaging }\end{array}$ & $\begin{array}{c}\text { Color Doppler } \\
\text { ultrasound group } n=48\end{array}$ & $\begin{array}{l}\text { Two-dimensional } \\
\text { ultrasound group } n=43\end{array}$ & $\mathrm{t} / \chi^{2}$ value & P-value \\
\hline Internal echo & & & 4.135 & 0.042 \\
\hline Solid type & $31(64.58)$ & $19(44.19)$ & & \\
\hline Cystic-solid type & $17(35.42)$ & $24(55.81)$ & & \\
\hline Posterior echo & & & 1.128 & 0.569 \\
\hline Uniformity & $10(20.83)$ & $7(16.28)$ & & \\
\hline Weak & $27(56.25)$ & $22(51.16)$ & & \\
\hline Enhanced & $11(22.92)$ & $14(32.56)$ & & \\
\hline Blood flow signal & & & 5.093 & 0.024 \\
\hline Obvious & $33(68.75)$ & $38(88.37)$ & & \\
\hline Not obvious & $15(31.25)$ & $5(11.63)$ & & \\
\hline Calcified lesions & & & 1.129 & 0.288 \\
\hline Yes & $16(33.33)$ & $19(44.19)$ & & \\
\hline No & $32(66.67)$ & $24(55.81)$ & & \\
\hline
\end{tabular}

\section{Results}

Comparison of size, form, boundary and location of patients with positive OSCSTs under color Doppler ultrasound and two-dimensional ultrasound. The size, form, boundary and location detected by color Doppler ultrasound in patients with OSCSTs were not significantly different from those detected by two-dimensional ultrasound $(\mathrm{P}>0.05)$, more details are shown in Table II.

Comparison of results of two kinds of ultrasound images in patients with positive OSCSTs. The real internal echo of color Doppler ultrasound was significantly higher than that of two-dimensional ultrasound, with significant statistical differences $(\mathrm{P}<0.05)$. The blood flow signal of color Doppler ultrasound was significantly higher than that of two-dimensional ultrasound, with significant statistical differences $(\mathrm{P}<0.05)$. There was no statistically significant difference in posterior echo and calcified lesion ( $P>0.05)$ (Table III, Figs. 1 and 2).

Comparison of the sensitivity, specificity and diagnostic accuracy of two kinds of ultrasound in detecting OSCST metastasis. The diagnostic sensitivity and the coincidence rate of color Doppler ultrasound for lymph node metastasis of OSCSTs were significantly higher than those of two-dimensional ultrasound $(\mathrm{P}<0.05)$. Differences were statistically significant $(\mathrm{P}<0.05)$ (Tables IV and V).

\section{Discussion}

OSCSTs can occur in women of any age group, and its manifestations of abdominal pain and abdominal distension become more and more obvious as the tumor grows larger, and even cause pedicle torsion and rupture in severe cases (16). Most of the OSCSTs can release steroid hormones and frequently cause corresponding clinical symptoms, such as menstrual disorder and hemorrhage of women caused by the increase of estrogen level, and masculinization characteristics of a few patients caused by the increase of androgen expression $(17,18)$. Ultrasound is generally used to assist the diagnosis of OSCSTs. Two-dimensional ultrasound provides early diagnosis for patients suspected of malignant tumors by presenting single-angle cross-sectional images of the human body. It has the advantages of non-invasiveness, repeatability, economy and high safety. At the same time, it is difficult to clearly express the three-dimensional morphological structure of ovary, which affects the accuracy of clinical differentiation of benign and malignant ovarian tumors $(19,20)$. Color Doppler ultrasound spatial stereogram vascular parameters can be used to observe neovascularization and blood cells in tumors, so as to judge the development of the disease (21). At present, there are few reports on the diagnosis of OSCSTs by color Doppler ultrasound and two-dimensional ultrasound. Therefore, we use pathological examination results as the gold standard to explore the diagnostic value of ultrasound imaging in OSCSTs, so as to provide a more accurate scheme for the diagnosis of OSCSTs patients.

In our study, the application value of color Doppler ultrasound and two-dimensional ultrasound in the diagnosis of OSCSTs was explored. First, we investigated the differences in size, form, boundary and location of tumors between color Doppler ultrasound and two-dimensional ultrasound. Our results showed that there were no significant differences in size, form, boundary and location of tumors between patients with positive OSCSTs and those of under two-dimensional ultrasound $(\mathrm{P}>0.05)$. Then we analyzed the diagnostic efficiency of color Doppler ultrasound and two-dimensional ultrasound for OSCSTs. The results showed that the diagnostic sensitivity and diagnostic coincidence rate of color Doppler ultrasound for lymph node metastasis of OSCSTs were significantly higher than those of two-dimensional ultrasound for lymph node metastasis of OSCSTs. The accuracy of color Doppler ultrasound combined with CA125 and CA199 detection was higher than that of two-dimensional ultrasound $(\mathrm{P}<0.05)$. Previous studies (22-24) have suggested that the sensitivity and 
Table IV. Diagnostic results of color Doppler ultrasound and two-dimensional ultrasound combined with CA125 and CA199 detection for ovarian sex cord-stromal tumors.

\begin{tabular}{|c|c|c|c|}
\hline Diagnostic results & Pathology (metastasis) & Pathology (non-metastasis) & Total \\
\hline \multicolumn{4}{|l|}{ Color Doppler ultrasound } \\
\hline Diagnosis (metastasis) & 36 & 3 & 39 \\
\hline Diagnosis (non-metastasis) & 2 & 7 & 9 \\
\hline Total & 38 & 10 & 48 \\
\hline \multicolumn{4}{|l|}{ Two-dimensional ultrasound } \\
\hline Diagnosis (metastasis) & 24 & 9 & 33 \\
\hline Diagnosis (non-metastasis) & 4 & 6 & 10 \\
\hline Total & 28 & 15 & 43 \\
\hline \multicolumn{4}{|c|}{ Color Doppler ultrasound combined with CA125 and CA199 detection } \\
\hline Diagnosis (metastasis) & 36 & 2 & 38 \\
\hline Diagnosis (non-metastasis) & 2 & 8 & 10 \\
\hline Total & 38 & 10 & 48 \\
\hline \multicolumn{4}{|c|}{ Two-dimensional ultrasound combined with CA125 and CA199 detection } \\
\hline Diagnosis (metastasis) & 24 & 6 & 30 \\
\hline Diagnosis (non-metastasis) & 4 & 9 & 13 \\
\hline Total & 28 & 15 & 43 \\
\hline
\end{tabular}

Table V. Diagnostic efficacy analysis of individual indicators and joint detection for ovarian sex cord-stromal tumors.

\begin{tabular}{|c|c|c|c|c|}
\hline Diagnostic value & $\begin{array}{c}\text { Color Doppler } \\
\text { ultrasound }\end{array}$ & $\begin{array}{c}\text { Two-dimensional } \\
\text { ultrasound }\end{array}$ & $\begin{array}{c}\text { Color Doppler } \\
\text { ultrasound } \\
+ \text { CA125 + CA199 }\end{array}$ & $\begin{array}{c}\text { Two-dimensional } \\
\text { ultrasound } \\
+ \text { CA125 + CA199 }\end{array}$ \\
\hline Sensitivity & $92.31 \%(36 / 39)$ & $65.12 \%(24 / 33)^{\mathrm{a}}$ & $94.74 \%(36 / 38)$ & $80.00 \%(24 / 30)^{\mathrm{b}}$ \\
\hline Specificity & $77.78 \%(7 / 9)$ & $60.00 \%(6 / 10)$ & $80.00 \%(8 / 10)$ & $69.23 \%(9 / 13)^{\mathrm{b}}$ \\
\hline Diagnostic coincidence rate & $89.58 \%(43 / 48)$ & $69.77 \%(30 / 43)^{\mathrm{a}}$ & $91.67 \%(44 / 48)$ & $76.74 \%(33 / 43)^{\mathrm{b}}$ \\
\hline
\end{tabular}

${ }^{\mathrm{a}} \mathrm{P}<0.05$ compared with color Doppler ultrasound; ${ }^{\mathrm{P}}<0.05$ compared with color Doppler ultrasound + CA125 + CA199.

diagnostic specificity of color Doppler ultrasound for ovarian malignant tumors are higher than those of two-dimensional ultrasound. Color Doppler ultrasound is more accurate than two-dimensional ultrasound in displaying abnormal spots of lesions and color blood signals. This proves our conclusion to some extent. Then we studied the relationship between features of OSCSTs imaging and pathological examination results of two kinds of ultrasound examinations. The results showed that the real internal echo of color Doppler ultrasound was significantly higher than that of two-dimensional ultrasound, with significant statistical difference $(\mathrm{P}<0.05)$. The blood flow signal of color Doppler ultrasound was significantly higher than that of two-dimensional ultrasound, with significant statistical difference $(\mathrm{P}<0.05)$. There is no significant statistical significance in posterior echo and calcified lesions $(\mathrm{P}>0.05)$, suggesting that the internal echo of OSCSTs tumor is related to pathological type. It is often dominated by solid hypoecho, and color Doppler has relatively high expression of color blood flow signals. Previous studies have shown that (25), ovarian sarcoma fibroma, as an uncommon OSCST, has been detected by ultrasound as a solid tumor with typical characteristics of well-defined hypoechoic masses. However, there are few specific research documents on OSCSTs ultrasound imaging. From this study, color Doppler ultrasound shows more solid mass and blood flow signals than two-dimensional ultrasound. There are no significant differences in general clinical pathological data and tumor characteristics between patients in the two groups. It is speculated that differences in internal echo and blood flow signals give color Doppler ultrasound higher diagnostic value for OSCSTs than two-dimensional ultrasound, and the diagnostic reliability is high. From our research, it seems that color Doppler ultrasound has more obvious diagnostic sensitivity for internal echo and blood flow signals in features of OSCST imaging.

In conclusion, this study shows that color Doppler ultrasound has high diagnostic value for OSCSTs, and its diagnostic results can be used as an important reference for diagnosis and treatment of OSCSTs in clinical practice.

\section{Acknowledgements}

Not applicable. 


\section{Funding}

This study was supported by the Science and Technology Department of Sichuan Province (grant no. 2019YFS0439).

\section{Availability of data and materials}

The datasets used and/or analyzed during the present study are available from the corresponding author on reasonable request.

\section{Authors' contributions}

GH, JZ and WX conceived and designed the study. GH, JZ, $\mathrm{ZY}, \mathrm{ZZ}$ and $\mathrm{YB}$ were responsible for the collection, analysis and interpretation of the data. GH drafted the manuscript. $\mathrm{JZ}$ and WX revised the manuscript critically for important intellectual content. All authors read and approved the final manuscript.

\section{Ethics approval and consent to participate}

The study was approved by the Medical Ethics Committee of Sichuan Provincial Hospital for Women and Children (Chengdu, China). Signed informed consents were obtained from the patients and/or the guardians.

\section{Patient consent for publication}

Not applicable.

\section{Competing interests}

The authors declare that they have no competing interests.

\section{References}

1. Hanley KZ and Mosunjac MB: Practical review of ovarian sex cord-stromal tumors. Surg Pathol Clin 12: 587-620, 2019.

2. Young RH: Ovarian sex cord-stromal tumours and their mimics. Pathology 50: 5-15, 2018.

3. Abdullazade S, Kosemehmetoglu K, Adanir I, Kutluay L and Usubutun A: Uterine tumors resembling ovarian sex cordstromal tumors: Synchronous uterine tumors resembling ovarian sex cord-stromal tumors and ovarian sex cord tumor. Ann Diagn Pathol 14: 432-437, 2010.

4. Haroon S, Zia A, Idrees R, Memon A, Fatima S and Kayani N: Clinicopathological spectrum of ovarian sex cord-stromal tumors; 20 years' retrospective study in a developing country. J Ovarian Res 6: 87, 2013.

5. Bairwa S, Satarkar RN, Kalhan S, Garg S, Sangwaiya A and Singh P: Sclerosing stromal tumor: A rare ovarian neoplasm. Iran J Pathol 12: 402-405, 2017.

6. Färkkilä A, Haltia UM, Tapper J, McConechy MK, Huntsman DG and Heikinheimo M: Pathogenesis and treatment of adult-type granulosa cell tumor of the ovary. Ann Med 49: 435-447, 2017.

7. Stuart GC and Dawson LM: Update on granulosa cell tumours of the ovary. Curr Opin Obstet Gynecol 15: 33-37, 2003.
8. Tamai K, Koyama T, Saga T, Kido A, Kataoka M, Umeoka S, Fujii $S$ and Togashi K: MR features of physiologic and benign conditions of the ovary. Eur Radiol 16: 2700-2711, 2006.

9. Kapadia SR, Ziada KM, L'Allier PL, Crowe TD, Rincon G, Hobbs RE, Bott-Silverman C, Young JB, Nissen SE and Tuzcu EM: Intravascular ultrasound imaging after cardiac transplantation: Advantage of multi-vessel imaging. J Heart Lung Transplant 19: 167-172, 2000.

10. Ng FC, Yam WL, Lim TYB, Teo JK, Ng KK and Lim SK: Ultrasound-guided percutaneous nephrolithotomy: Advantages and limitations. Investig Clin Urol 58: 346-352, 2017.

11. Dala-Krishna P: Ultrasound image processing to render threedimensional images from two-dimensional images. Acoust Soc Am J 131: 4231, 2004.

12. Franke S, Lieske H, Fischer A, Büttner L, Czarske J, Räbiger D and Eckert S: Two-dimensional ultrasound Doppler velocimeter for flow mapping of unsteady liquid metal flows. Ultrasonics 53: 691-700, 2013.

13. Porter MB: Polycystic ovary syndrome: The controversy of diagnosis by ultrasound. Semin Reprod Med 26: 241-251, 2008.

14. Chen D, Peng L and Yang P: Clinical value of transvaginal color Doppler ultrasound in differential diagnosis of benign and malignant ovarian tumor. Medical J Wuhan Univ 35: 893-895, 2014 (In Chinese).

15. Shah D, Shah S, Parikh J, Bhatt CJ, Vaishnav K and Bala DV: Doppler ultrasound: A good and reliable predictor of ovarian malignancy. J Obstet Gynaecol India 63: 186-189, 2013.

16. Tinelli A,Pellegrino M, Malvasi A and Lorusso V: Laparoscopical management ovarian early sex cord-stromal tumors in postmenopausal women: A proposal method. Arch Gynecol Obstet 283 (Suppl 1): 87-91, 2011.

17. Bufa A, Farkas N, Preisz Z, Poór V, Páger C, Szukits S, Farkas B and Gőcze PM: Diagnostic relevance of urinary steroid profiles on ovarian granulosa cell tumors: Two case reports. J Med Case Rep 11: 166, 2017.

18. Cecchetto G, Ferrari A, Bernini G, Alaggio R, Collini P, Virgone C, Terenziani M, Dall'igna P, Cozza R, Conte M, et al: Sex cord stromal tumors of the ovary in children: A clinicopathological report from the Italian TREP project. Pediatr Blood Cancer 56: 1062-1067, 2011.

19. Holsbeke CV and Timmerman D: Sex cord-stromal tumors: Clinical setting and ultrasound findings. In: Ovarian Neoplasm Imaging. Springer Science + Business Media, New York, 2013.

20. Chen QN, Zhang Y and Tan JX: Diagnosis of ovarian teratomas with two-dimensional ultrasound. Zhong Nan Da Xue Xue Bao Yi Xue Ban 29: 319-321, 2004 (In Chinese).

21. Saad AA: Vessel recognition in color doppler ultrasound imaging. 2008. https://digital.lib.washington.edu/researchworks/ handle/1773/5976.

22. Zanetta G, Vergani P and Lissoni A: Color Doppler ultrasound in the preoperative assessment of adnexal masses. Acta Obstet Gynecol Scand 73: 637-641, 1994.

23. Cohen LS, Escobar PF, Scharm C, Glimco B and Fishman DA: Three-dimensional power Doppler ultrasound improves the diagnostic accuracy for ovarian cancer prediction. Gynecol Oncol 82: 40-48, 2001.

24. Liu GA, Ye RZ and Xu M: Analysis of 50 cases of traumatic retinal detachment diagnosed by color Doppler ultrasound and two-dimensional ultrasound. Int J Ophthalmol 14: 1263-1265, 2014.

25. Chen H, Liu Y, Shen LF, Jiang MJ, Yang ZF and Fang GP: Ovarian thecoma-fibroma groups: Clinical and sonographic features with Res. Ovarian pathological comparison. J Ovarian Res 9: 81, 2016.

This work is licensed under a Creative Commons Attribution-NonCommercial-NoDerivatives 4.0 International (CC BY-NC-ND 4.0) License. 